\title{
Тенденции развития силовой электроники
}

\author{
М. Макушин ${ }^{1}$
}

УДК 621.316 | ВАК 05.27 .01

\begin{abstract}
Силовая электроника и мощные полупроводниковые приборы имеют большое значение в народном хозяйстве и тесно связаны с другими отраслями. Их можно рассматривать как поддерживающую инфраструктуру, обеспечивающую функционирование других отраслей экономики. В настоящее время основным потребителем изделий силовой электроники является обрабатывающая промышленность. В перспективе же пальму первенства у нее может отобрать автомобильная промышленность - за счет расширения сферы использования электромобилей/гибридных автомобилей, а также автономных транспортных средств.
\end{abstract}

иловая электроника взаимосвязана с другими отраслями. С одной стороны, ее развитие оказывает воздействие на другие отрасли, открывая перед ними новые возможности. С другой стороны, развитие существующих отраслей и появление новых ведет к росту энергопотребления и стимулирует развитие силовой электроники и мощных полупроводниковых приборов, с упором на повышение энергоэффективности. К основным сферам использования силовой электроники и мощных полупроводниковых приборов можно отнести промышленные электродвигатели, ветроустановки, гелиотехнику, зарядную инфраструктуру, электромобили / гибридные автомобили, железнодорожную индустрию, высоковольтные линии электропередач, источники бесперебойного электропитания. В сфере мощных полупроводниковых приборов также наблюдаются подвижки. Господствующие сейчас кремниевые приборы в перспективе будут замещаться GaN- и Sic-приборами. Более того, возможно развитие сектора приборов типа GaN-на-SiC, совмещающих достоинства обеихтехнологий, и обещающего стать перспективным направлением развития мощных полупроводниковых приборов.

\section{РЫНОК СИЛОВОЙ ЭЛЕКТРОНИКИ: ОБЩИЕ ТЕНДЕНЦИИ}

Две исследовательские фирмы Yole Développement (Лион, Франция) и System Plus Consulting (Нант, Франция), входящие в группу компаний Yole (Yole Group of Companies), недавно провели совместное исследование современного состояния и перспектив развития рынка силовой электроники. В рамках данного исследования было подтверждено, что как большинство изготовителей, так и наибольшие объемы продаж силовой электроники в настоящее время ориентированы на промышленные предприятия. Однако, ожидаемое в ближайшие годы взрывообразное развитие электромобилей и гибридных транспортных

Цнии «Электроника», главный специалист, mmackushin@gmail.com. средств, а также соответствующей инфраструктуры приведет к существенному изменению ситуации. К 2024 году и далее все большая часть силовой электроники будет потребляться автопроизводителями. Правда, ввиду того, что электромобили и гибридный транспорт ориентированы на снижение потребляемой мощности, а для промышленной электроники эти требования не столь существенны, доля промышленной электроники в энергопотреблении еще долгое время будет превышать долю автомобильной промышленности. Отмечается, что в современных условиях основными факторами развития автомобильной промышленности, особенно сектора электромобилей/гибридных автомобилей, являются как научно-технический прогресс, так и требования рынка (рис. 1).

\section{ВЗАИМНОЕ ВЛИЯНИЕ СИЛОВОЙ ЭЛЕКТРОНИКИ И ДРУГИХ ОТРАСЛЕЙ}

Развитие рынка силовой электроники оказывает воздействие и на другие рынки и сферы человеческой деятельности. Увеличение энергопотребления, развитие экологически чистых транспортных средств вызывают потребность в расширении электрификации, увеличении применения возобновляемых источников энергии и т. п. Для обслуживания электромобилей и гибридного транспорта необходимо расширять сеть зарядных станций как в городах, так и за их пределами. Учитывая, что на автомагистралях будут необходимы большие станции для быстрой зарядки многих автомобилей одновременно, потребность в развитии электросетей становится очевидной.

Для лучшего обеспечения потребностей в электроэнергии электросетей также необходимо развивать сектор систем накопления энергии. Предполагается осуществлять развертывание крупных систем солнечных панелей в непосредственной близости к зарядным станциям.

Только вот вопрос использования возобновляемых источников энергии для обеспечения питания электромобилей и гибридных машин вызывает сомнения. До сих 


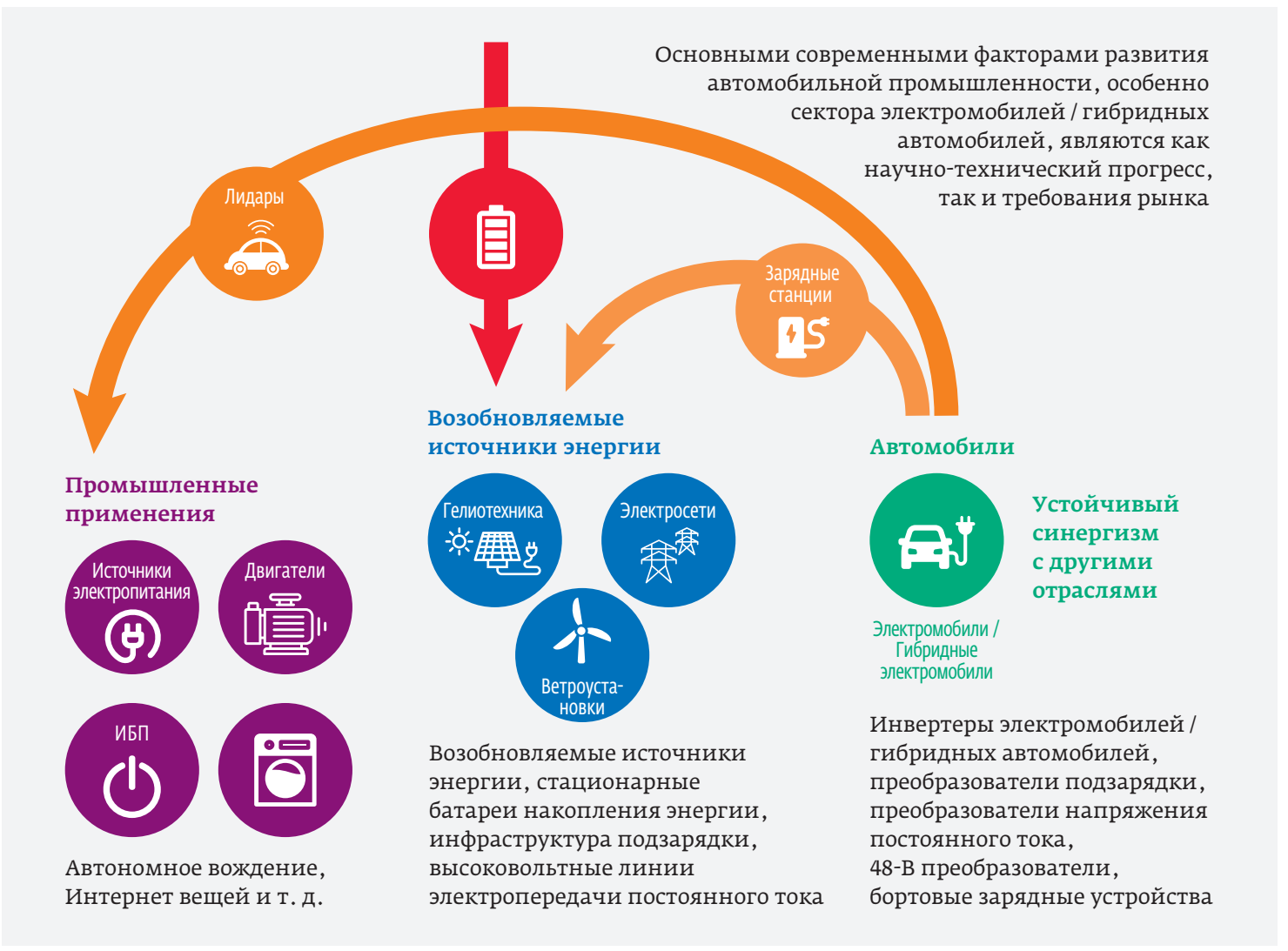

Рис. 1.

Основные факторы и тенденции развития силовой электроники.

Источник: Status of the Power Electronics Industry 2019 report, Yole Développement, 2019

пор цена производимого гелиотехникой «солнечного электричества" существенно выше, чем на газовых или угольных электростанциях. Да и поля солнечных панелей занимают много места. Что же касается ветроустановок, то места их размещения из-за инфразвука становятся малопригодными для жизни, хотя их развертывание и приводит к увеличению продаж инверторов.

Кроме того, по мере распространения средств автономного вождения потребуется больший объем обмена данными, в том числе по системам V2X-связи", увеличение

* V2X (Vehicle-to-Everything) - обобщенное название технологий связи автомобиль-автомобиль (V2V) и автомобильинфраструктура (V2I), которые являются основным единым решением в среде "подключенного автомобиля". В рамках данной концепции дорожные службы, инфраструктура, автомобили, водители и другие участники дорожного движения должны сотрудничать друг с другом для обеспечения наиболее эффективной, безопасной, надежной и комфортной поездки. Связь V2Х сформирует один из основных вкладов в концепцию кооперативной мобильности. Связь V2X основана на технологии радиосвязи DSRC на частоте 5,9 ГГц; это технология двусторонней беспроводной связи малого радиуса действия, разработанная специально для движущихся объектов. В целом, она позволяет автомобилям обмениваться данными с другими автомобилями и придорожным оборудованием, датчиками и участниками, подобно связи по Wi-Fi, но используя специальные эффективные сетевые функции. числа центров обработки данных, бо́льшее число радарных и лидарных систем, а также других технологий инфраструктурной поддержки.

Аналитики Yole подчеркивают устойчивый синергизм между всеми упомянутыми секторами и ростом автомобильного рынка, в частности за счет электромобилей / гибридных транспортных средств. Воздействие данных факторов в целом выльется в устойчивый рост индустрии силовой электроники - ее продажи возрастут с 53,4 млрд долл. в 2018 году до 72,6 млрд долл. в 2024 году (рис. 2).

\section{МОЩНЫЕ ПОЛУПРОВОДНИКОВЫЕ ПРИБОРЫ}

При рассмотрении рынка на приборном уровне оказывается, что наибольшие продажи дискретных приборов приходятся на МоП полевые транзисторы. Однако наибольший рост наблюдается в секторе приборов высокой мощности, которые требуют биполярных транзисторов с изолированным затвором (IGBT) или SiC-приборов, обеспечивающих желаемую эффективность. Правда, по прогнозам Yole Développement, в период 2018-2024 годов CAGR продаж IGBT и MOП полевых транзисторов составит 3,7 и 4,6\% соответственно. При этом рост продаж МОП полевых транзисторов обусловлен именно проникновением на данный рынок SiC-приборов - их потребление в электромобилях продемонстрирует в прогнозируемый период наибольшие темпы прироста [1]. 


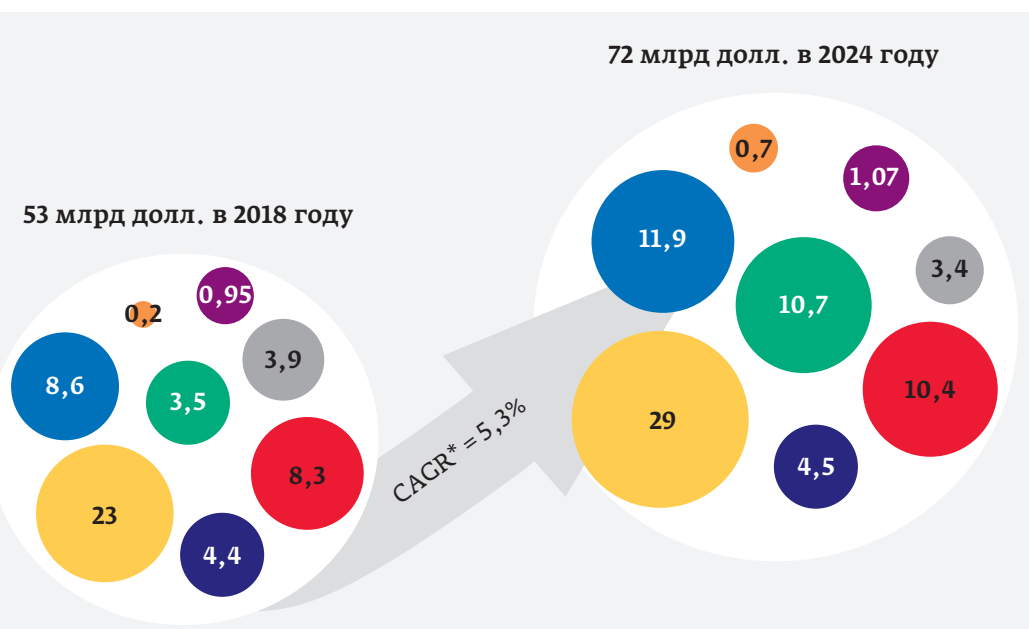

* CACR - среднегодовой темп роста в сложных процентах

Двигатели Ветроустановки Гелиотехника Зарядная инфраструктура Высоковольтные линии электропередачи постоянного тока Электромобили и гибридные автомобили Железнодорожная сфера Источники бесперебойного питания (ИБп)

Рис. 2. Эволюция рынка силовой электроники за 2018-2024 годы в разбивке по применениям. Источник: Status of the Power Electronics Industry 2019 report, Yole Développement, 2019

\section{GaN и SiC MОЩНЫЕ ПОЛУПРОВОДНИКОВЫЕ ПРИБОРЫ: ПОЗИЦИИ СТОРОННИКОВ}

В долгосрочной перспективе мощные полупроводниковые приборы на GaN и на SiC постепенно заменят свои аналоги на основе кремния в основном потому, что использование мощных GaN- или SiC-транзисторов может привести к более простым и эффективным решениям для хранения энергии. По прогнозам, к2025 году совокупный рынок GaNи Sic-приборов будет оцениваться более чем в 3 млрд долл. (данные GaN System) и будет в значительной степени зависеть от возобновляемых источников энергии и электромобилей. Кроме того, в мире все больше и больше центров обработки данных (ЦОД), гибридных автомобилей, промышленных двигателей.

Требования по питанию растут на каждом рынке, глобальные потребности в электроэнергии, как ожидается, увеличатся с 25000 ТВт. 4 в настоящее время до 38000 ТВТ. 4 в 2050 году. В мире 8 млн ЦОД используют 2-3\% мирового энергопотребления, и эта доля вырастет до 5\% и более. Промышленные применения потребляют 30\%, их энергопотребление также растет. Электромобили становятся крупными потребителями электроэнергии - в 2040 году на них придется до 5\% ее мирового потребления. GaN мощные полупроводниковые приборы уменьшают потери во всех этих системах.

GaN-технология играет важную роль в продвижении инноваций в мощных полупроводниковых приборах. Она позволяет удовлетворить новые потребности, добиться увеличения мощности и производительности, большей эффективности и уменьшения размеров.

По сравнению с приборами с широкой запрещенной зоной, такими как SiC-транзисторы, GaN-приборы обладают рядом преимуществ, в том числе с точки зрения ценообразования, доступности материалов, возможностей создания конструкций под низкие и средние требования к напряжению тока. Системы, созданные с использованием GaN мощных полупроводниковых приборов, обладают лучшей плотностью мощности, чем системы на SiC-приборах. К преимуществам также относятся низкий заряд затвора, нулевой обратный ток восстановления и плоская выходная емкость. Все это обеспечивает высокие характеристики переключения. Цены на GaN мощные полупроводниковые приборы легко масштабировать так, чтобы со временем они стали конкурентными с ценами кремниевых приборов, особенно ввиду того, что GaN мощные полупроводниковые приборы производятся на кремниевых пластинах.

Сторонники GaN мощных полупроводниковых приборов утверждают, что их приборы прошли существенную эволюцию. Если несколько лет назад GaN-технология была в основном в университетских исследовательских лабораториях, то сегодня такие признанные фирмы, как Denso, GaN Systems, Sonnen и Supermicro, участвуют в конференциях и дискуссиях и информируют научное сообщество о том, как GaN мощные полупроводниковые приборы улучшают параметры систем, в которых они используются. Сейчас системы с мощными GaN полупроводниковыми приборами начинают коммерциализироваться, появляется гораздо больше возможностей для инновационного процесса в этой области. GaN-приборы с напряжением 100 и 650 В соответствуют требованиям энергосистем в настоящее время и в ближайшей перспективе [2] .

Возвращаясь к SiC мощным полупроводниковым приборам можно отметить, что их сторонники, наоборот, считают, что их технология превосходит GaN-технологию. Недавно корпорация Cree, мировой лидер в области SiC-технологии объявила о планах по созданию «кластера карбида кремния» на восточном побережье США. Предполагается создание крупнейшего в мире завода (в штате Нью-Йорк) по производству карбида кремния. Крометого, корпорация построит совершенно новый завод (Марси, шт. Нью-Йорк) 
по обработке 200-мм пластин, на которых будут производиться SiC мощные полупроводниковые приборы для автомобилей и SiC мощные РЧ-приборы. Наконец, будет расширяться существующая в Г. Дарем (шт. С. Каролина) мегафабрика по производству Sic-пластин и других материалов. Она находится в "Треугольнике науки»" и пользуется поддержкой расположенных в нем университетов.

Создание нового завода является частью ранее объявленного проекта по резкому увеличению производственных мощностей фирмы Wolfspeed, подразделения Cree. Данный завод будет заниматься и Sic-, и GaN-технологиями. Это будет высокоавтоматизированное предприятие с увеличенной производительностью. Проект осуществляется в рамках стратегического партнерства с властями штата Нью-Йорк и другими государственными и местными учреждениями и организациями, решение о строительстве в Нью-Йорке позволит как продолжить в будущем расширение потенциала, так и значительно сократить чистую себестоимость на производственных мощностях Cree. В результате Creе будет и в дальнейшем осуществлять переход с кремниевой технологии на SiC-технологию. Ее подразделение Wolfspeed будет выпускать приборы для электромобилей, средств связи поколений 4G/5G и промышленной электроники.

В рамках партнерства Cree инвестирует около 1 млрд долл. в строительство, оснащение оборудованием и другие расходы нью-йоркского предприятия. Штат НьюЙорк предоставит грант в размере 500 млн долл. через инвестиционный фонд Empire State Development, a Cree получит право на дополнительные местные стимулы и льготы, а также использование оборудования и инструментальных средств Политехнического института Университета штата Нью-Йорк (SUNY). В результате компания рассчитывает получить чистую экономию капитала в размере около 280 млн долл. на инвестициях в расширение мощностей на 1 млрд долл., которые будут осуществляться до 2024 года. Кроме того, реализация проекта позволит на 25\% увеличить объемы производства по сравнению с ранее запланированными показателями. После завершения строительства, в 2022 году, площадь нового объекта составит

* Research Triangle Park (RTP) - Треугольник науки, Исследовательский треугольник. Район в центральной части штата Северная Каролина, в графстве Дарэм (Durham County). "Треугольник» расположен между университетскими городками университетов Дьюка (Duke University, г. Дарем), штата Северная Каролина (North Carolina State University, г. Роли) и Северной Каролины (University of North Carolina, г. Чапел-Хилл). Территория более 2830 га. Создан в 1959 году с целью привлечения в регион новых промышленных предприятий. Сегодня здесь расположены многие компании, работающие в области высоких технологий, медицинские центры и др. Более 50\% из примерно 40 тыс. сотрудников (2003) компаний района работают в транснациональных корпорациях до 44,6 тыс. м², примерно одна четверть из которых будет представлять собой пространство чистых комнат, которые смогут обеспечить возможность расширения мощностей по мере необходимости. Это еще больше улучшит конкурентные позиции Creе на рынке и ускорит внедрение SiC в ряде быстрорастущих отраслей промышленности [3].

IGВТ-модули также демонстрируют существенный рост продаж, что объясняется их соответствием требованиям высокой отдачи мощности и плотности, предъявляемым основными силовыми применениями. Сегодня на данные модули приходится 23\% общего объема рынка. Новые применения, такие как системы накопления энергии, инфраструктура подзарядки и электромобили, в ближайшие годы потребуют модули с различными уровнями мощности и требованиями к надежности, что приведет к увеличению разнообразия данных приборов [1]

\section{СТРАТЕГИЯ КОРПОРАЦИИ ЗТMicroelectronics}

Корпорация STMicroelectronics (Женева, Швейцария) сделала ставку на технологию SiC в качестве одной из важных составляющих стратегии развития и извлечения доходов. Она намерена захватить 30\% рынка SiC-приборов, емкость которого в 2025 году составит 3,7 млрд долл. (данные STMicroelectronics).

$\mathrm{SiC}$ является одной из технологий с широкой запрещенной зоной все чаще используемых поставщиками полупроводниковых приборов для создания высокомощных и высокоэффективных решений электрификации транспортных средств. Однако из-за ограниченности предложения и экосистемных проблем, таких как, например, глобальный дефицит SiC-пластин, STMicroelectronics осуществляет ряд шагов, обеспечивающих контроль над всей цепочкой поставок. К таким шагам, в частности, относится недавнее соглашение с Cree, гарантирующее поставку ее подразделением, фирмой Wolfspeed, 150-мм необработанных и эпитаксиальных SiC-пластин, а также покупка 55\% акций у шведского производителя SiC-пластин фирмы Norstel с намерением в конечном итоге полностью поглотить ее.

Руководство STMicroelectronics полагает, что через 30 лет более 50\% рынка мощных полупроводниковых приборов будет производиться на основе SiC-технологии. В настоящее время фирма закупает слитки и подложки на стороне, а их обработка осуществляется на заводе в Катании (Италия). у STMicroelectronics уже есть планы интеграции Norstel в свою цепочку поставок. Сотрудничество с Cree также расширяет для STMicroelectronics возможности маневра и интеграции. В данное время SiC-приборы швейцарской фирмы выпускаются на пластинах диаметром 150 мм. После окончательного поглощения Norstel и связанных с ним исследовательских мощностей их планируется перевести на работу с пластинами диаметром 200 мм (К 2025 г.). 


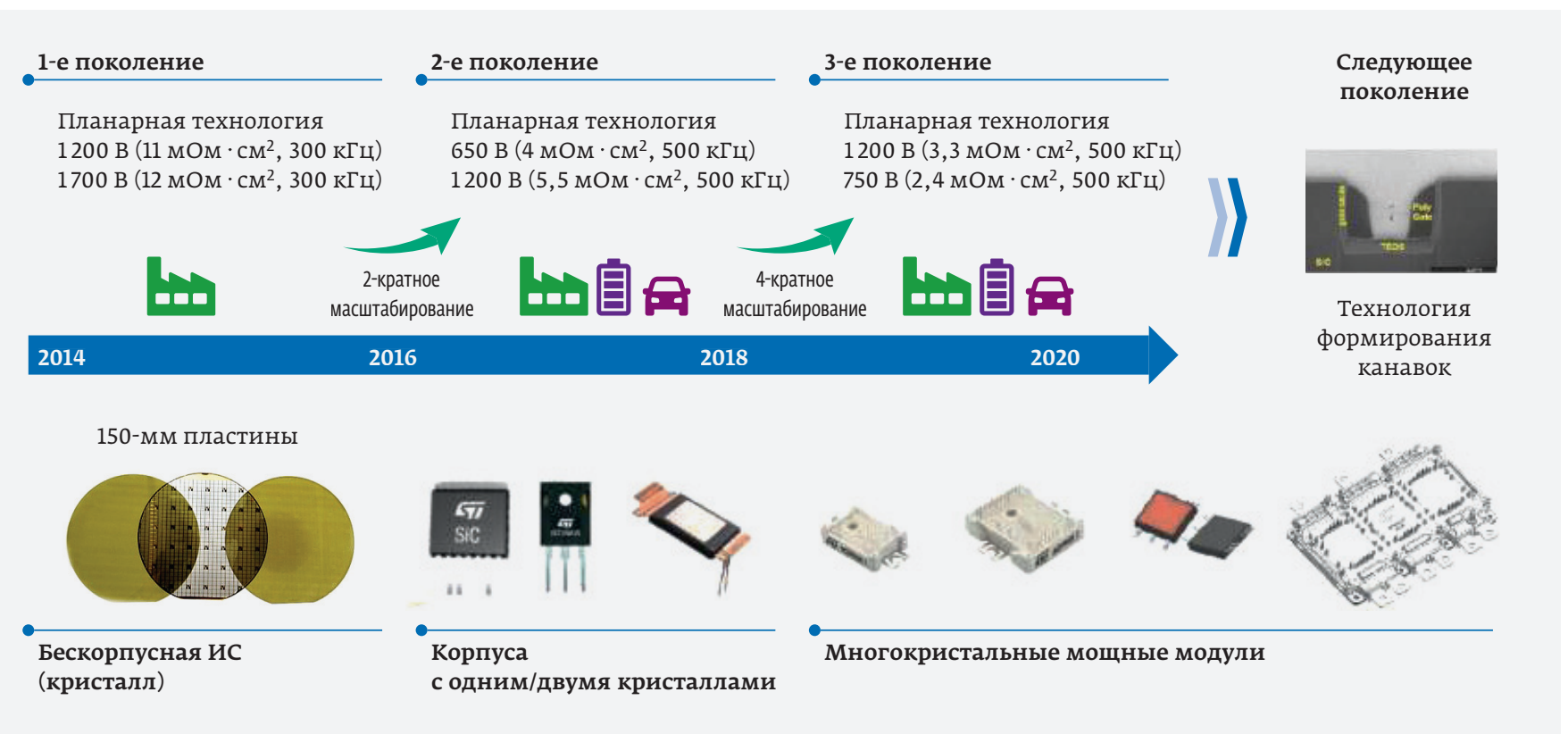

Рис. 3. Маршрутная карта развития SiC-технологии. Источник: STMicroelectronics

По итогам 2018 года доход STMicroelectronics в области SiC-технологии составил 100 млн долл., в 2019 году его предполагается довести до 200 млн долл., а в 2025 году до 1 млрд долл. Для достижения поставленных задач придется модернизировать и взять под контроль всю цепочку поставок. Основными целевыми рынками SiC-приборов STMicroelectronics станут Интернет вещей, интеллектуальное вождение (автономные транспортные средства), регулирование потребления электроэнергии и управление режимом электропитания. Руководство фирмы намерено осуществлять последовательное инвестирование своих разработокв соответствии с объемом получаемых доходов.

В принципе, STMicroelectronics предстоит решить две проблемы, по крайней мере, в краткосрочной перспективе: цепочка поставок и стоимость / издержки. Поставщики сырья и приборов должны согласовать объемы поставок, а изготовителям SiC-приборов еще продемонстрировать, что MOП полевые транзисторы (MOSFET) на SiC являются энергоэффективным решением для электромобилей.

Вторая задача заключается в снижении затрат по мере наращивания производства. Возникает необходимость масштабирования приборов, увеличения диаметра обрабатываемых пластин (для снижения удельных издержек), снижения стоимости материалов и оптимизации конструкции приборов/модулей. Завод STMicroelectronics в Катании производит как бескорпусные ИС, так и корпусированные модули. В соответствии с маршрутной картой STMicroelectronics по развитию SiC MOSFET в 2020 году предполагается параллельно с освоением третьего поколения планарной технологии освоить перспективную технологию формирования канавок (рис. 3).
$\mathrm{SiC}$ по сравнению с кремнием более труден в обработке, что и является одной из причин роста затрат. Это, в свою очередь, является сдерживающим фактором широкого освоения и применения SiC-технологии. Кроме того, SiC обладает высокой присущей материалу дефектностью, которая дает о себе знать в процессе производства подложки, приводя к необходимости использования более сложного технологического процесса с целью обеспечения необходимых качества и надежности. Ввиду того, что SiC как материал достаточно труден в обработке, есть необходимость использования более сложного производственного процесса на основных этапах операций диффузии. Следовательно, SiC-приборы будут дороже (кремниевых). Однако специалисты STMicroelectronics указывают на конечную экономию средств от ихприменения. Например, в электромобиле SiC-приборы могут первоначально увеличить затраты на 300 долл., но конечная экономия может достигнуть 2 тыс. долл. - за счет снижения стоимости аккумуляторных источников питания, занимаемого ими и SiC-приборами пространства в электромобиле и вопросов охлаждения.

Завод в Катании производит не только SiC-приборы, в его производстве также используется технология на основе нитрида галлия (GaN). Tak, STMicroelectronics сотрудничает в области технологии "GaN-на-кремнии" для 5G средств / систем с корпорацией Macom.

STMicroelectronics работает с SiC-технологией с 1996 года, в 2004 году фирма произвела свои первые SiC-приборы, а в 2009 году - первые SiC MOSFET (имеются версии на напряжение 1200 и 650 B). STMicroelectronics, как и ряд других фирм, производит мощные SiC-приборы для автомобилей, и они являются одним из ключевых 
элементов электрификации транспортных средств. Производство SiC-пластин диаметром 150 мм фирма начала в 2017 году, при этом, помимо ИС для автомобильных применений, STMicroelectronics производит приборы для таких применений, как солнечные инверторы, промышленные электроприводы, домашнее оборудование, адаптеры источников питания (силовые адаптеры) [4].

\section{ОСВОЕНИЕ ТЕХНОЛОГИИ "GaN-на-SiC" - ПЕРСПЕКТИВА?}

При развитии новых технологий часто бывает так, что казалось бы несовместимые подходы, могут применяться совместно, порождая, благодаря синергетическому эффекту, нечто новое и более совершенное. Первые упоминания о GaN-на-SiC относятся к2002 году, а данные о начале опытного и серийного производства - к началу 2010-х годов. В чем преимущества этой технологии? Она позволяет создавать мощные транзисторы, демонстрирующие (в определенных диапазонах) наивысшие в отрасли показатели выходной мощности и усиления. При этом их использование позволяет уменьшать размеры систем по сравнению с системами, использующими другие, ранее упомянутые технологии.

B принципе, технология "GaN-Ha-SiC" по сравнению c "GaN-на-кремнии» более сложная и дорогая. Основным определяющим фактором является производительность, а не цена. Именно поэтому ее основная область применения технологии "GaN-на-SiC" - приборы и системы военного назначения, беспроводная инфраструктура. Также она частично охватывает такие области, как волоконная оптика, кабельное телевидение, малые наземные спутниковые станции (VSAT) (рис. 4).

Основными производителями мощных GaN-Ha-SiC транзисторов и схем являются корпорации Cree, Integra, Microsemi и Microwaves\&RF. Бесспорным лидером является корпорация Cree [5]. Корпорация Integra специализируется на НЕМТ РЧ мощных транзисторах для импульсных лазерных систем [6], корпорация Microsemi производит мощные импульсные GaN-на-SiC транзисторы для радаров [7], а корпорация Microwaves\&RF - GaN-Ha-SiC мощные HEMTтранзисторы с частотой до 18 ГГц (также для радаров) [8].

$$
\because \because *
$$

Появление новых отраслей вызывает изменение парадигмы развития силовой электроники и мощных полупроводниковых приборов. В сфере мощных полупроводниковых приборов GaN- и SiC-технологии постепенно заменяют кремниевую технологию. Причина - использование GaN- и SiC-транзисторов может привести к выходу на более простые и эффективные решения хранения энергии. Интересные перспективы открываются и связи с технологией "GaN-на-Sic".

\section{ЛИТЕРАТУРА}

1. Barbarini E., Villamor A. The power of electronics // I-Micronews. 09.12. 2019.

https://www.i-micronews.com/the-power-of-electronics/ ?utm_source=ZohoCampaigns\&utm_campaign=iMN_13Sept2019_Asia\&utm_medium=email\&cn-reloaded=1.

2. Maurizio Di Paolo Emilio. GaN is driving power semiconductors // EE Times. 09.24.19. https://www.eetimes.com/document.asp?doc_id=1335143.

3. Shannon D. Cree Announces Update to Capacity Expansion Plan // Semiconductor Digest. September 23. 2019 https://www.semiconductor-digest.com/2019/09/23/creeannounces-update-to-capacity-expansion-plan/4.

4. Nitin D. ST Bets Future on Silicon Carbide. EE Times, 04.01.19. https://www.eetimes.com/document.asp?doc_id=1334505.

5. Cree RF GaN-on-SiC Foundry Process \& Product Capabilities Overview https://www.youtube.com/watch?v=bF327zukd90

6. GaN-on-SiC RF and Microwave Power Transistors for the Latest Pulsed Radar System Designs https://www.integratech. com/rf-power-transistors-for-new-designs/

7. Microsemi Power Discretes \& Modules https://www.microsemi.com/product-directory/606-discretes.

8. Microwaves\&RF. GaN-On-SiC Devices Power DC To $18 \mathrm{GHz}$ https://www.mwrf.com/analog-semiconductors/gan-sicdevices-power-dc-18-ghz\#close-olyticsmodal. 


\section{[L]HTERPAC}

\section{ИМС ЧЕТЫРЕХКАНАЛЬНОГО СУПЕРВИЗОРА ПИТАНИЯ 5322СХ045 КАТЕГОРИИ КАЧЕСТВА «ВП»}

Окончена ОКР «Визирь-1», в рамках которой разработана микросхема категории качества «ВП» $5322 \mathrm{CX045}$ четырехканального супервизора питания с контролем фиксированных напряжений питания 3,3 и 2,5 В и с контролем двух настраиваемых уровней напряжений от двух независимых источников питания с формированием сигнала «сброс». Микросхема предназначена для применения в РЭА специального назначения. Микросхема изготавливается в металлокерамическом CLCC-корпусе 5119.16-А и функционирует при температуре от -60 до $125^{\circ} \mathrm{C}$. Функциональные аналоги микросхемы - микросхемы MAX6709IUB, MAX6709JUB компании Maxim Integrated. Технические условия AEHB.431350.475-02 TY.

Таблица 1. Основные параметры и функциональные особенности микросхемы

\begin{tabular}{|l|c|}
\multicolumn{1}{|c|}{ Наименование параметра } & Норма параметра \\
\hline Напряжение питания, B & $2,0 \div 5,5$ \\
\hline $\begin{array}{l}\text { Пороговое напряжение на входе IN2 формирования } \\
\text { сигнала «сброс», Uтн1, B }\end{array}$ & $3,0 \div 3,15$ или $2,85 \div 3,0$ \\
\hline $\begin{array}{l}\text { Пороговое напряжение на входе IN3 формирования } \\
\text { сигнала «сброс», Uтн2, B }\end{array}$ & $2,25 \div 2,38$ или $2,12 \div 2,25$ \\
\hline $\begin{array}{l}\text { Настраиваемое пороговое напряжение формирования } \\
\text { сигнала ошибки, UтнА, B }\end{array}$ & $0,984 \div 1,016$ \\
\hline Длительность сигнала сброса, мс & $140 \div 280$ \\
\hline
\end{tabular}

\section{Основные фоунции микросхемы}

Контролируемые уровни напряжений питания фиксированных каналов составляют 3,3 и 2,5 В, допуск отклонения контролируемого уровня напряжения от номинального 5 или 10\%. Два настраиваемых канала для возможности контроля уровней напряжения питания двух независимых источников питания. Встроенная функция «сброс от внешней кнопки». Микросхема содержит следующие основные блоки: источник опорного напряжения, блок резистивных делителей, блок компараторов, схему формирования сигнала «сброс», коммутатор, схему управления выходом. Каждый канал микросхемы (по входам IN1, IN2, IN3, IN4) имеет свой независимый компаратор. Фиксированные каналы IN2, IN3 контроля уровней напряжений питания 3,3 и 2,5 В имеют встроенные резистивные делители, напряжения выходов которых сравниваются с опорным напряжением. К двум настраиваемым каналам предполагается подключение внешних резистивных делителей, рассчитанных для контроля источников питания с разными напряжениями.

Микросхемы обладают следующими функциональными возможностями:

- формирование сигналов «сброс» $\overline{R E S E T}$ и RESET при контроле уровня напряжения питания 3,3 B на входе IN2 и при контроле уровня напряжения питания 2,5 B на входе IN3;

- формирование сигналов «сброс» $\overline{R E S E T}$ и RESET от внешней кнопки по входу $\overline{\mathrm{MR}}$ (функция ручного сброса);

- формирование сигналов ошибки по выходам $\overline{\mathrm{OUT} 1} \div \overline{\mathrm{OUT4}}$ при контроле уровней напряжений источников питания на входах IN1 $\div$ IN4.

Микросхема имеет три основные функции. Первая функция - контроль уровней напряжения источников питания 3,3 и 2,5 В по фиксированным каналам IN2, IN3. Внутренний источник опорного напряжения и аналоговый компаратор анализируют уровни напряжений источников питания на входах IN2, IN3. В случае возникновения сбойной ситуации, когда уровень напряжения питания на входе IN2 или IN3 опускается ниже уровня порогового напряжения $U_{T H 1}$ или $U_{T H 2}$, вырабатывается внутренний сигнал ошибки питания, переводящий сигналы «сброс» на выводах RESET и RESET в активное состояние. Выводы RESET и RESET будут оставаться в активном состоянии до тех пор, пока уровни напряжения источников питания остаются ниже пороговых напряжений сброса (Uтн1 или Uтн2). После возвращения уровня напряжения источника питания на входе IN2 или IN3 в устойчивое состояние сигналы «сброс» остаются активными не менее 140 мс, позволяя источнику питания и процессору стабилизироваться. Вторая функция - «сброс от внешней кнопки». Микросхема имеет вход ручного сброса $\overline{\mathrm{MR}}$ от внешней кнопки. При подаче на вход $\overline{\mathrm{MR}}$ импульса активного низкого уровня фрормируются сигналы «сброс» на выводах RESET и RESET. Сигналы остаются в активном состоянии не менее 140 мс после того, как $\overline{\mathrm{MR}}$ переключится обратно с низкого уровня на высокий. Вход $\overline{\mathrm{MR}}$ имеет встроенный подтягивающий к питанию резистор порядка 20 кОм. Третья ффункция - мониторинг состояния уровней напряжений внешних источников питания. Микросхема имеет два аналоговых входа (настраиваемых канала) IN1, IN4, которые соединены с входами соответствующих компараторов, на вторые входы которых подается опорное напряжение, вырабатываемое внутренним источником опорного напряжения. 
Рис. 1. Условное графическое обозначение

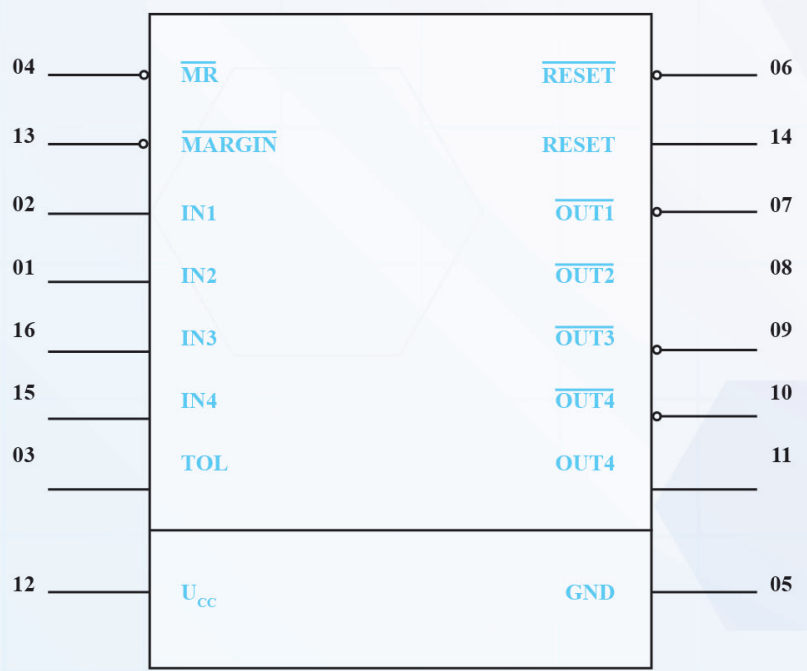

Настраиваемые каналы позволяют пользователю контролировать два внешних источника питания с разными напряжениями. Для задания контролируемого уровня напряжения внешних источников питания используются внешние резистивные делители напряжения, подключаемые к входам IN1 и IN4. При обнаружении падения уровня напряжения на определенном настраиваемом канале ниже порогового уровня напряжения Uтна микросхема формирует импульс на соответствующем выходе активного низкого уровня (для входа IN4 дополнительно формируется еще и прямой сигнал активного высокого уровня на выходе OUT4).

Вход TOL определяет допуск отклонения контролируемого уровня напряжения от номинального для фиксированных каналов IN2, IN3:

5\% - при подключении входа TOL к общему выводу GND; 10\% - при подключении входа TOL к выводу Ucc.

Микросхема имеет вход $\overline{\mathrm{MARGIN}}$ блокировки выходов. При подаче на вход $\overline{\mathrm{MARGIN}}$ импульса активного низкого уровня, все выходы микросхемы переводятся в неактивное состояние, что позволяет блокировать сигналы сброса при настройке системы. Вход МARGIN имеет встроенный подтягивающий к питанию резистор порядка 20 кОм. Выходы микросхемы $\overline{R E S E T}$ и OUT1 $\div \overline{\text { OUT4 }}$ имеют слабую, порядка 10 мкA, подтяжку к питанию и схемотехнически выполнены таким образом, что при их подключении через внешний резистор к источнику с напряжением питания, большим Uсc микросхемы, ток утечки с этого источника на Uсc отсутствует. В январе 2019 года подано предложение для включения микросхемы 5322СХ045 в перечень ЭКБ 02.

Рис. 2. Временная диаграмма работы микросхемы

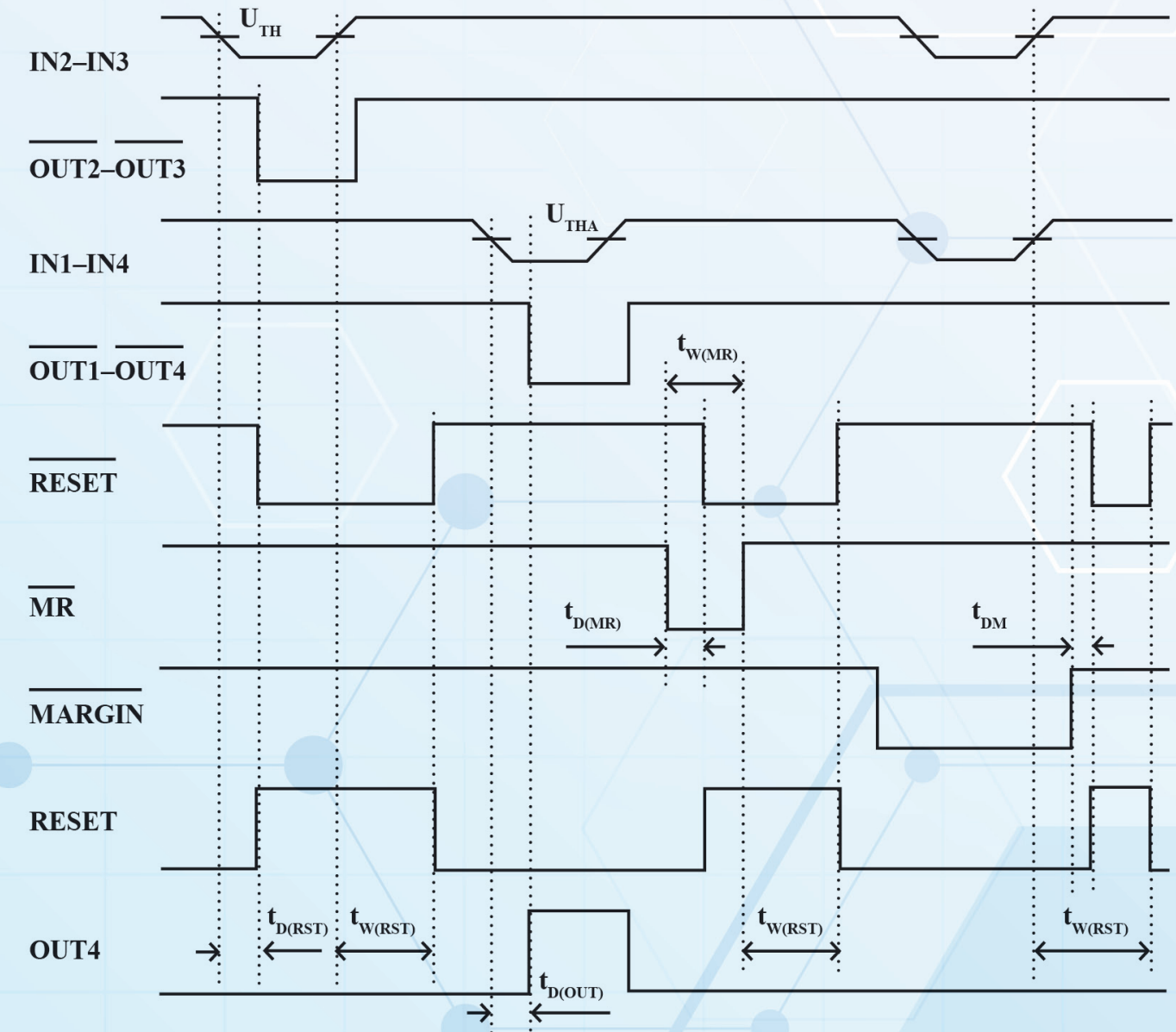

